\title{
A transformação do comportamento mecanicista diante de fatores motivacionais no ambiente de trabalho da empresa Baiana de Águas e Saneamento de Paulo Afonso - EMBASA \\ Paula Normanda dos Anjos Vicente, Fernanda Roda de Souza Araújo Cassundé
}

Resumo: A pesquisa aborda o que influencia os atributos mecanicistas que permeiam as organizações, analisando os elementos básicos sobre o comportamento humano no seu ambiente de trabalho, de forma que seja possível mediar uma trajetória de motivação humana que admita mudanças e consequentemente, permita formas alternativas de desempenho do trabalho. Os fatores que influenciam notoriamente a motivação foram traçados atentando que estes podem variar com a cultura. Considerando que o tema deste estudo envolve o que transforma a motivação e consequentemente, o comportamento, a pesquisa demanda os métodos explicativo, descritivo e metodológico. Um questionário foi aplicado de forma censitária na Embasa, que trouxe resultados satisfatórios quanto à compreensão dos aspectos mais relevantes de insatisfação e também dos aspectos que tornam os funcionários motivados. Após a análise, verificou-se que há fatores motivacionais bastante relevantes, que já ocorrem, mas precisam tornar-se mais frequentes, bem como outros que são passíveis de implantação na Embasa.

Palavras-chave: Motivação, ambiente de trabalho, comportamento

\section{The Transformation of the Mechanical Behavior before Motivational Factors in Bahia Company of Water and Sanitation Work Environment in Paulo Afonso - EMBASA}

\begin{abstract}
The research addresses what influences the mechanistic attributes that permeate organizations, analyzing the basic elements of human behavior in the workplace, so that you can mediate a trajectory of human motivation that admits changes and consequently, allow alternative forms of performance work. The factors that influence motivation notoriously have been drawn paying attention to these may vary with culture. Considering that the subject of this study involves which transforms the motivation and consequently, the behavior, the research demand the explanatory, descriptive and methodological methods. A questionnaire was administered to census form in Embasa, which brought satisfactory results regarding the understanding of the important aspects of dissatisfaction and also aspects that make employees motivated. After analysis, it was found that there are quite relevant motivational factors, which already occur, but need to become more frequent as well as others who are capable of implementation in Embasa.
\end{abstract}

Keywords: Motivation, work environment, behavior

\footnotetext{
${ }^{1}$ Especialização em Gestão Pública pela Universidade do Vale do São Francisco - UNIVASF.

Autor correspondente: paula.vicente@embasa.ba.gov.br;

${ }^{2}$ Graduação em Administração pela Universidade Federal de Pernambuco (2001) e Mestrado em Administração pela Universidade Federal de Pernambuco (2004). Doutoranda em Administração no programa DINTER-UNIVASF/PROPAD. Atualmente é professora Assistente II do colegiado de Administração da Universidade Federal do Vale do São Francisco (UNIVASF) e Pesquisadora de projeto apoiado pelo CNPq cujo tema refere-se ao desenvolvimento de competências docentes para EAD.
} 


\section{Introdução}

O que motiva as pessoas e o seu comportamento no ambiente de trabalho, é um complexo fenômeno constante em todas as organizações a todo o tempo. Analisar a motivação e suas variantes é o que possibilita encontrar possibilidades e estratégias que tragam um conteúdo que seja significativo para os agentes públicos.

O comportamento humano individual dentro de uma organização envolve questões sobre a habilidade pessoal, a motivação e a satisfação. No âmbito do setor público, há componentes bastante próprios para a análise do fenômeno motivacional, a saber, os condicionantes normativos das relações entre Administração Pública e agente público, a natureza do produto do setor público (bens e serviços públicos), a dinâmica das atividades internas ao ambiente de trabalho, as relações pessoais etc. Essas especificidades diferenciam as organizações públicas das privadas e têm forte impacto no comportamento humano. (BERGUE, 2012)

O ambiente em que operam os órgãos e entidades do setor público caracteriza-se por relativo grau de estabilidade, notadamente em face da natureza das atividades reservadas ao poder público. Tal estabilidade não deve confrontar a eficiência do serviço prestado, que requer aprimoramento constante frente às invariáveis que incidem sobre a organização. Atualmente, a acessibilidade é elemento cada vez mais emergente ao cidadão, que o torna gradativamente mais exigente e faz, de acordo Bergue (2012, p. 9) "incidir sobre o arranjo institucional do Estado uma tensão por mudança visando à sua adaptação às novas contingências, pela via da inovação".

A motivação no trabalho está sempre flutuando. Nunca é completamente estável, nem no ápice, nem no declive. $\mathrm{O}$ que se busca com este estudo não é alcançar uma estabilidade, mas sim, encontrar formas de mantê-la passível de movimento. Quando um agente público estagna sua motivação, seu comportamento tende a ser mecanicista e sua desenvoltura no trabalho limitada tão quanto à sua motivação está. Portanto, tornar a motivação suscetível à transformação possibilita que a administração pública alcance uma estrutura sistêmica, que é considerada por Balbi e Valadares (2008, p. 1) "como essencial para sobrevivência em um mundo cada vez mais impulsionado por mudanças aceleradas".

Os incentivos são fatores importantes para alcançar a motivação das pessoas. Se os funcionários são bem remunerados, realizam tarefas que os motivam e tem o reconhecimento da gerência, vão realizar suas tarefas com eficiência e bom desempenho. Porém, a excelente remuneração por si só, não é o bastante para motivar os funcionários.

A dificuldade de motivar servidores públicos estáveis se torna mais complexa quando não se pode dispor de mecanismos potencialmente motivadores, vinculados à ascensão e aumento da 
remuneração. Porém, isso não deve levar à conclusão de que não há alternativas que se possam aplicar em relação a esta necessidade. Santos $(2009$, p.6), sugere que "um simples elogio pode significar expressiva mudança na eficácia da equipe de trabalho."

Sabemos que a motivação humana para o trabalho permanece ainda como um dos grandes desafios dentro da realidade das organizações. Apesar das inúmeras e complexas teorias, na prática, a motivação ocasionalmente é vista com simplicidade, entretanto, com maior atenção é possível identificar que as pessoas estão desmotivadas em seu trabalho. Observa Vieira (2011, p. 1):

[...] a ideia de motivação no serviço público não está tão distante da realidade, mas os administradores públicos devem se conscientizar de sua missão e definir suas próprias metas pessoais e estimular seu crescimento profissional e melhorar a imagem da Administração Pública no país.

Para que o servidor público tenha o perfil de empreendedor público, deve-se criar um ambiente propício ao afloramento de comportamentos comuns em empreendedores. É necessário fomentar uma cultura empreendedora nas organizações públicas. Porém esta cultura não é fomentada de forma rápida. É necessário, primeiramente planejá-la. Isto significa ao gestor pensar em uma cultura empreendedora que sustente um comportamento empreendedor na organização pública. (BALBI e VALADARES, 2008).

A importância da dimensão humana no âmbito do serviço público é tão grandiosa, que é ela quem determina e os limites e possibilidades em termos de organização do trabalho. Para tanto, desenvolver o potencial das pessoas é de grande prioridade, pois amadurece o ser na vida profissional, social e pessoal, fazendo com que o individuo percorra um caminho de amadurecimento e valoração de sua real potencialidade e como consequência, excelência organizacional. Diante disso, entender como resgatar a motivação no ambiente de trabalho com práticas gerenciais adequadas, é uma alternativa promotora para o crescimento e sustentabilidade organizacional.

Considerando o ambiente de trabalho, o tipo de incentivo que de fato ocasione impulso pode variar, sendo preciso inicialmente reconhecer como as pessoas interagem e pensam dentro do local em que estão inseridas. A compreensão destes traços de cultura em face da realidade permite ao gestor elaborar um processo de construção consistente, incluindo identificar os incentivos de melhor estímulo para a sua equipe, que tragam resultados mais substanciais para a mudança esperada.

Um servidor motivado atende um triplo objetivo ao mesmo tempo: trazendo benefícios para os funcionários, que se sentem recompensados pelo trabalho realizado; para a própria empresa que visa à obtenção de lucro e; ao cidadão usuário, que usufrui de um serviço público prestado com maior eficiência. Atualmente, o problema de manter a motivação que define o comportamento humano esperado no trabalho, tem levantado pesquisas e discussões. Acerca disto, Bergue (2012, p. 7) explana: 
Observamos que a diversidade de obras publicadas sobre o comportamento humano nas organizações e suas variantes é ampla, mas podem ser considerados ainda incipientes, embora crescentes, os esforços de produção técnica e acadêmica desse tema nas organizações públicas.

É muito pertinente o estudo da motivação na EMBASA, onde as novas gerações de colaboradores apresentam-se mais facilmente passíveis de ser motivadas do que os colaboradores mais antigos, que estão revestidos de um perfil mecanicista e inclusive, indissolúveis a lidar com a tecnologia. Além disto, comportamentos passados podem afetar o comportamento futuro num processo cíclico de aprendizagem. Daí a ênfase para que estas consequências do comportamento humano possam ser positivamente manipuladas nas diferentes situações.

A análise e a melhoria da produtividade nas organizações atuais, não devem ter apenas em conta variáveis ligadas ao capital físico, tecnológico e humano da empresa, mas também incluírem preocupações com a identidade psicológica da organização. Assim sendo, as organizações também precisam pautar-se em valores e, não apenas por normas e procedimentos, enfatizando o aprendizado contínuo a partir da integração do sentir, pensar e agir nas relações humanas diárias. (MASCARENHAS, 2009; SILVA, 2009).

Todo o processo de gestão de uma organização é desenvolvido pelas pessoas cujas atitudes, conhecimentos e comportamentos são variáveis de desempenho importantes que influenciam o trabalho. Se os objetivos organizacionais são alcançados através das pessoas, considerar a importância do ser humano para o equilíbrio organizacional é fundamental para entendermos como se dá a transformação do comportamento mecanicista diante de fatores motivacionais no ambiente de trabalho da Empresa Baiana de Águas e Saneamento de Paulo Afonso - EMBASA.

O campo de pesquisa onde o problema está inserido - EMBASA - se trata de uma sociedade de economia mista de capital autorizado, pessoa jurídica de direito privado, com regime celetista de contratação de pessoal por meio de concurso público, tendo como acionista majoritário o Governo do Estado da Bahia.

O ultimo concurso da empresa, realizado em 2010, aumentou o número de trabalhadores próprios, o que resultou em mais funcionários fixos, estáveis e em sua maioria jovens, com os quais a organização pode se planejar e alavancar necessidades a ser supridas por meio da atividade destes. Em contrapartida, é necessário pensar em maneiras de manter estes novos ingressos entusiasmados, regidos pela motivação que o ambiente de trabalho oferece e voltados às necessidades da organização. 


\section{Discussão Teórica}

A pesquisa se inicia pelo exame de elementos conceituais básicos sobre o comportamento humano nas organizações e o fenômeno da motivação das pessoas no ambiente de trabalho, com destaque para as especificidades do setor público. Conforme aborda Pires, 2006, p 81 "As pessoas que atuam nas organizações são agentes que contribuem para esse intercâmbio constante, sendo seus valores componentes para a formação da cultura da organização".

Para melhor conhecer a relação das pessoas com os processos organizacionais, em particular os processos de trabalho, é preciso conhecer os pressupostos que, nos afirma Arruda, M, 2006, p 42 "informam a organização desses processos, reforçam o comportamento existente e enfatizam como este comportamento se ajusta ao ambiente organizacional.".

\section{A Motivação}

Para Rodrigues (2014 p. 255), a motivação é vista como "uma força propulsora, cujas origens se encontram na maior parte do tempo escondidas no interior do indivíduo". Ampliando a sua definição prática, Gomes (2003 p.6) afirmou que "motivação possui o significado de sentir-se motivado para fazer algo".

A falta de motivação pode comprometer fortemente a força de trabalho de uma organização, e os seus efeitos no trabalho - provocados por um conjunto de políticas geradoras de incerteza e insegurança - podem gerar graves problemas tanto para as organizações quanto para as pessoas. Em relação aos locais de trabalho, pode haver perdas de seus padrões de qualidade e produtividade, e quanto aos trabalhadores, as consequências negativas estão ligadas à saúde física e mental, ao estresse, ao absenteísmo, à baixa produtividade e ao fraco desempenho no trabalho, sem contar a falta de comprometimento com sua organização. (BRUNELLI, 2008)

\section{O Comportamento e o ambiente}

Balbi e Valadares (2008) expõem que o comportamento é um fenômeno cultural que possui fatores e atitudes comportamentais que variam de um lugar para o outro, dependendo do meio em que se vive. 
Para Brunelli (2008), o ambiente interno em que convivem os membros de uma organização está relacionado ao seu grau de motivação e satisfação. O clima organizacional é influenciado pelas crenças e valores que regem as relações interpessoais, determinando o que é bom ou ruim para todos. Desta forma, o ambiente de trabalho é favorável quando permite a satisfação pessoal de cada um, e desfavorável quando frustra suas necessidades pessoais. No entanto, Vieira (2011), salienta que os impulsos externos do ambiente são condicionantes do comportamento de cada indivíduo o que também afeta o nível motivacional.

Mascarenhas (2009) depreendeu que sob o prisma da administração estratégica, a motivação tem de caminhar lado a lado com os valores contidos no ambiente organizacional. Dentre esses valores devemos destacar a comunicação organizacional que é fundamental para o sucesso do processo de motivação.

O comportamento pode ser entendido como a manifestação observável do produto da interação de fatores no ambiente. A falta destes fatores de estímulo confere ao indivíduo um caráter de automatismo ao comportamento. O estudo do comportamento humano nas organizações deve contemplar a investigação das relações entre os contextos organizacionais, sistemas de recompensa, motivação dos funcionários e padrões de resultados. (GOMES, 2003; RODRIGUES, 2014)

\section{Os fatores transformadores da motivação}

A motivação aumenta ou diminui de intensidade na proporção inversa do aumento ou diminuição da intensidade da satisfação relativa às necessidades do indivíduo. Fatores motivadores, proporcionados de forma adequada, possibilitam incrementar o nível de satisfação no trabalho. (GOMES, 2003 p. 6).

A atribuição de responsabilidades é um fator potencialmente influente. Delegar atividades realmente úteis permite que o funcionário se sinta como ator importante da missão da empresa. É pertinente que ele se sinta merecedor desta responsabilidade de forma a querer retribui-la com um desempenho de confiança. Neste viés, Rodrigues (2014 p. 258), corrobora que "os funcionários públicos são mais motivados para o trabalho quando têm tarefas desafiadoras, claramente entendidas e que eles acreditam ser importantes e alcançáveis". Aliado a isso, é necessário que na empresa haja políticas de carreira e remuneração que contemplem os fatores de qualificação e desempenho capazes de justificar as diferenciações remuneratórias.

Outro forte fator motivador, a Remuneração, é um dos elementos mais importantes, pois compensa, direciona, motiva e remunera o trabalho e a contribuição das pessoas. Se bem feita, assegura que os profissionais sejam remunerados de forma adequada à responsabilidade que possuem, 
bem como pela contribuição que agregam através do conhecimento aplicado em determinado trabalho. (ARRUDA, J, 2012).

Para Brandao (2014 p. 98), "A remuneração [...] relaciona-se fortemente com a insatisfação". É preciso notar a importância da variável compensatória dada ao trabalhador, pois, é um fator de aperfeiçoamento da organização, impulsionador de processos e de melhoria e aumento da produtividade. $\mathrm{O}$ estímulo na gratificação, combinado a outros elementos motivacionais determinam o sucesso de um sistema de incentivo aplicado pela empresa.

\section{Método}

Considerando que o problema deste estudo envolve a transformação da motivação e consequentemente, do comportamento, é possível depreender que esta pesquisa envolve uma demanda que a caracteriza como explicativa, uma vez que buscará esclarecer quais fatores contribuem de alguma forma, para ocorrência deste fenômeno. Esta pesquisa também possui o método descritivo como base para suas explicações. Neste tipo de pesquisa são analisadas hipóteses ou inferenciais que se relacionam com a descrição de determinada situação, surgindo variáveis importantes no estudo. Aqui, foi abordado como o comportamento muda de acordo o ambiente, sendo que este mesmo varia e influencia a motivação. (CRESWELL, 2007 p.124)

Para o levantamento de elementos que contribuam para a transformação da motivação, será realizada a pesquisa bibliográfica, uma vez que utiliza livros e artigos de revistas sobre o tema. "A pesquisa bibliográfica é o estudo sistematizado desenvolvido com base em material publicado em livros, revistas, jornais, redes eletrônicas, isto é, material acessível ao público em geral”. (Vergara, 2005, p. 48). Assim, através da experiência descrita por outros autores em outras organizações foi possível alencar fatores que de fato funcionem como motivacionais. Assim, a pesquisa do problema proposto englobou os métodos explicativo, descritivo e bibliográfico.

A investigação empírica no local onde ocorreu o fenômeno se deu na EMBASA - Empresa Baiana de Águas e Saneamento, unidade de Paulo Afonso, Bahia. O local dispõe de elementos (pessoas, cultura, gestores, normatização) que explicam a manifestação do comportamento humano, incorporando assim como meio de pesquisa, a de campo.

O universo ou população desta pesquisa constituiu-se de funcionários efetivos lotados na EMBASA - Unidade de Paulo Afonso, totalizando 62 pessoas. $\mathrm{O}$ estudo abrange o numero total dos componentes da população, portanto, não haverá uma amostra, ou subconjunto do universo. Do universo populacional, excetuaram-se como sujeitos de pesquisa os gerentes e supervisores, por 
exercerem atividades como gestores da população de interesse do estudo. Por se tratar do estudo de uma população relativamente pequena, esta pesquisa poderá ainda, permitir a construção de cadastros para utilização de amostragem em outras pesquisas.

Para a coleta de dados primários em pesquisa de campo foi utilizada a observação e questionário individual, que foi o principal norteador. O questionário foi construído conforme critérios sugeridos por Creswell, (2007, p.189) "os passos de coleta de dados incluem estabelecer as fronteiras para o estudo, coletar informações [...] bem como estabelecer o protocolo para registrar informações [...] do local e das pessoas propositadamente selecionadas". Antes de ser encaminhado aos participantes da pesquisa, o questionário foi previamente avaliado e aprovado pela gerencia regional da Unidade.

Composto de 10 questões objetivas, o participante não precisou se identificar. As alternativas eram diferentes em cada questão, e também diferiam na ordem em que expressavam grau de satisfação, para não induzir à marcação mecânica. Dados complementares foram solicitados, sendo estes: sexo, faixa etária, tempo de serviço e escolaridade. Os questionários foram entregues pessoalmente, e cada respondente foi orientado a preenchê-lo individualmente. Todos foram informados sobre o objetivo e o fim da pesquisa.

Além dos critérios mencionados, as perguntas foram formuladas considerando o plano de cargos e salários oferecido pela Embasa, bem como as possibilidades de ascensão e classificação por mérito existentes e as não existentes. Com isso, foi possível reconhecer as mudanças necessárias a ser adotadas para transformação da motivação, atendendo aos objetivos desta pesquisa. Para obtenção dos resultados, a análise do projeto adotou o procedimento censitário no qual toda a população serviu como base para conhecimento e considerações a respeito do assunto. A pesquisa apresenta, além do caráter quantitativo, a abordagem qualitativa por meio da pesquisa bibliográfica.

\section{Análise De Dados}

\section{Perfil dos respondentes}

As mulheres representam 25\% dos respondentes. A média de idade delas é de 38 anos. 59\% das mulheres está há 4 anos ou menos na empresa, e 17\% possuem mais de 30 anos de serviço na Embasa. $73 \%$ possuem nível superior ou um grau de escolaridade acima e ocupam cargo de nível médio e possuem formação acima da exigida.

Os homens são a maioria da força de trabalho. Representando $75 \%$ dos respondentes, possuem idade média de 41,5 anos. $35 \%$ dos homens está há 4 anos ou menos na empresa, e proporcional às 
mulheres, $17 \%$ destes também possuem mais de 30 anos de Embasa. 25\% dos homens ocupam cargo de nível médio e possuem formação acima da exigida.

\section{Fatores Motivacionais para os funcionários públicos da Embasa}

A tabela 1 sintetiza os resultados obtidos, referentes à satisfação dos servidores da Embasa de Paulo Afonso-BA. Os aspectos representam as questões levantadas em ordem crescente. O percentual foi obtido a partir das opções atribuídas por respondente, e as categorias retratam o que foi estabelecido como base de opções de respostas para cada aspecto questionado. A tabela foi dividida em comportamento, competências, remuneração e potencialidades.

Tabela 1 - Satisfação dos servidores da Embasa frente aos fatores motivacionais

\begin{tabular}{|c|c|c|c|}
\hline \multirow{7}{*}{ 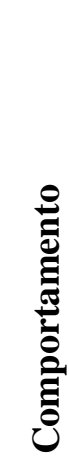 } & Aspecto & Categorias & Percentual \\
\hline & \multirow{3}{*}{$\begin{array}{l}\text { 1. Aumento do empenho no trabalho } \\
\text { com o decorrer do tempo de serviço }\end{array}$} & Sim & $23 \%$ \\
\hline & & Igualmente & $65 \%$ \\
\hline & & Menor & $12 \%$ \\
\hline & \multirow{3}{*}{$\begin{array}{l}\text { 2. Estimulo ocasionado ao assumir a } \\
\text { responsabilidade de nova tarefa }\end{array}$} & Reduzido & $2 \%$ \\
\hline & & Não afetado & $56 \%$ \\
\hline & & Acrescido & $42 \%$ \\
\hline \multirow{12}{*}{ 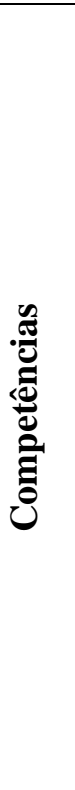 } & Aspecto & Categorias & Percentual \\
\hline & \multirow{3}{*}{$\begin{array}{l}\text { 3. Gosta das atividades/atribuições que } \\
\text { exerce }\end{array}$} & Gosto muito & $63 \%$ \\
\hline & & Não gosto & $2 \%$ \\
\hline & & Gosto em parte & $35 \%$ \\
\hline & \multirow{4}{*}{$\begin{array}{l}\text { 4. Aceitaria uma mudança de } \\
\text { setor/atribuições para ampliar os } \\
\text { conhecimentos }\end{array}$} & Aceitaria & $81 \%$ \\
\hline & & Não aceitaria & $10 \%$ \\
\hline & & Não acho & $9 \%$ \\
\hline & & necessária & \\
\hline & \multirow{4}{*}{$\begin{array}{l}\text { 5. A avaliação de desempenho em } 2014 \text { o } \\
\text { deixa mais motivado }\end{array}$} & Concordo & $23 \%$ \\
\hline & & Discordo & $31 \%$ \\
\hline & & Concordo & $46 \%$ \\
\hline & & Parcialmente & \\
\hline
\end{tabular}

Fonte: Elaborado pelo autor com dados da pesquisa 
Os primeiros dois aspectos retratam claramente um comportamento mecanicista na percepção da maioria, em que nem o tempo de experiência no serviço e nem a oportunidade de assumir uma nova tarefa são vistos como fatores motivadores. Vale ressaltar que dentre os que não apresentam maior empenho no trabalho em relação ao tempo, $70 \%$ representam os que entraram na Embasa no último concurso, realizado há 4 anos. Isto pode significar que os funcionários já entraram desmotivados ou que desde sua entrada até o momento, o tempo não trouxe fatores motivacionais.

Os itens 3 e 4 demonstram um nível de interesse e motivação maiores, em que a maioria gosta das atribuições que lhe foram repassadas, aspecto essencial para a desenvoltura de partes do comportamento. O interesse está predominante no item 4, em que mais de $80 \%$ aceitariam uma troca de setor e/ou atividades, que representa que os funcionários estão disponíveis para ampliar seus conhecimentos e, como consequência, atender às necessidades da empresa no que tange a uma mudança nas atividades.

A avaliação de desempenho por competência de 2014, tratada no item 5, não expressa influência na motivação. Trata-se da primeira avaliação realizada na empresa. O mérito é dado por competência. 59\% dos respondentes trabalham há mais de 10 anos na empresa, o que reflete que a avaliação, mesmo inovadora, implantada de forma padronizada e que visa o desenvolvimento profissional, não é um fator impulsionador da motivação. (EMBASA, 2014)

\begin{tabular}{l|l|ll}
\hline & Aspecto & Categorias & Percentual \\
\cline { 2 - 4 } & 6. Remuneração em comparação com a & Totalmente compatível & $8 \%$ \\
de outras categorias profissionais que & Parcialmente compatível & $54 \%$ \\
\cline { 2 - 4 } & realizam trabalho similar & Totalmente incompatível & $38 \%$ \\
\cline { 2 - 4 } & 7. A politica de cargos e salários atual da & Sim & $2 \%$ \\
embasa, é satisfatória & Não & $52 \%$ \\
\cline { 2 - 4 } & 8. A implantação da retribuição por & Parcialmente Satisfatória & $46 \%$ \\
\hline
\end{tabular}

Fonte: Elaborado pelo autor com dados da pesquisa

Nas questões 6 e 7, que avaliam o salário e plano de cargos e salários, temos resultados relevantes. Pouco mais da metade está parcialmente satisfeita com a sua remuneração em comparação com a de outras categorias que realizam trabalho similar e pouco mais de $1 / 3$ o consideram totalmente 
incompatível. Este fator se relaciona com o plano de cargos, que está avaliado com insatisfatório por mais da metade dos respondentes.

Expresso no item 8, o incentivo à qualificação foi bastante aceito como proposta motivadora. Considerando que a EMBASA não possui retribuição por titularidade, a adoção desta gratificação seria um fator bastante motivador para os funcionários que já possuem formação acima da exigida, e também para aqueles que desejam obtê-la.

\begin{tabular}{|c|c|c|c|}
\hline \multirow{7}{*}{ 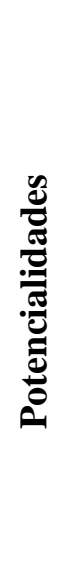 } & Aspecto & Categorias & Percentual \\
\hline & \multirow{3}{*}{$\begin{array}{l}\text { 9. Aumentaria seu envolvimento no } \\
\text { trabalho }\end{array}$} & $\begin{array}{l}\text { Oportunidades de mostrar sua } \\
\text { capacidade }\end{array}$ & $25 \%$ \\
\hline & & $\begin{array}{l}\text { Reconhecimento pelo que } \\
\text { executa }\end{array}$ & $30 \%$ \\
\hline & & Progresso na carreira & $45 \%$ \\
\hline & \multirow{3}{*}{ 10. Aumentaria sua motivação } & Reconhecimento do chefe & $17 \%$ \\
\hline & & O não desvio da função & $25 \%$ \\
\hline & & Cursos de Capacitação & $58 \%$ \\
\hline
\end{tabular}

Fonte: Elaborado pelo autor com dados da pesquisa

Os aspectos 9 e 10, correlacionados, mostram-nos que o envolvimento no trabalho seria maior na ocorrência de oportunidades de progresso na carreira e que a motivação seria aumentada principalmente mediante cursos de capacitação. Considerando que a realização de cursos já ocorre na empresa, a sua maior frequência ou a sua melhor distribuição entre os funcionários o configura um fator motivador mais expressivo.

\section{Conclusões}

Este trabalho buscou identificar, na EMBASA - Empresa Baiana de Águas e Saneamento, os fatores preponderantes para motivação e consequentemente, mudança no comportamento mecanicista no trabalho. Os resultados foram obtidos majoritariamente através da aplicação de questionários a empregados lotados na Unidade de Paulo Afonso. 
Dentre os aspectos abortados no questionário, três questões foram reconhecidas como motivadoras. A primeira é a satisfação nas atribuições que lhe foram repassadas, motivação esta por algo já existente. A segunda é a possibilidade de mudança de atribuições e/ou setor, algo passível de ocorrer. A terceira e com maior índice positivo é a adoção pela empresa da retribuição por qualificação além da exigida pelo cargo. Além destes fatores identificados, a motivação e o envolvimento no trabalho seriam aumentados com a progressão na carreira e a participação em cursos de capacitação. Em contrapartida, a remuneração em relação às atribuições foi considerada totalmente incompatível e a atual política de cargos e salários foi considerada insatisfatória, influenciando o comportamento mecanicista.

$\mathrm{O}$ reconhecimento de elementos motivadores e/ou desmotivadores ofereceu à Embasa a oportunidade de compreender quais fatores podem transformar o comportamento mecanicista perante aspectos motivacionais. Todavia, deve-se ressaltar que o intuito não consistiu em exaurir o assunto, mas sim, servir de entrada para pesquisas e ampliar a compreensão do tema, tendo como objetivo a identificação do que pode contribuir para a excelência na prestação de serviços oferecidos pela empresa.

Destarte, a relevância da motivação das pessoas para um ambiente de trabalho é fundamental para que as empresas públicas - com usuários cada vez mais exigentes - acompanhem esta crescente necessidade, munindo-se, sobretudo, de prestadores de serviço envolvidos para executar as estratégias traçadas e as mudanças fundamentais.

\section{Referências}

ARRUDA, J. F. A influência da remuneração por desempenho na satisfação dos trabalhadores. Estudo de caso em uma empresa comercial. Dissertação, 2007. (Mestrado em Sistemas de Gestão), Universidade Federal Fluminense - UFF, Niterói, RJ.

ARRUDA M. F. Cultura organizacional e inovação: estudo de caso em um hospital privado com características de inovação no município de São Paulo. Dissertação, 2006. Fundação Getúlio Vargas. Escola de administração de empresas de São Paulo.

BALBI, R. V; VALADARES, J. L. Estratégia e Planejamento: Bases da Cultura Empreendedora? Um Ensaio Teórico. Simpósio de Gestão da Inovação Tecnológica, 25. Anais. Brasília (DF). 2008. Disponível em: < http://www.anpad.org.br/diversos/trabalhos/Simp\%C3\%B3sio/simposio_2008/2008 _SIMPOSIO532.pdf >. Acesso em: 30 Jun. 2014.

BERGUE, S. T. Cultura e Mudança Organizacional. Florianópolis: Departamento de Ciências da Administração / UFSC; [Brasília]: CAPES: UAB, 2010.

BERGUE, S. T. - 2. ed. reimp. Comportamento Organizacional - Florianópolis: Departamento de Ciências da Administração / UFSC; [Brasília]: CAPES: UAB, 2012. 
BRANDÃO, I. F.; LIMA, L. C.; CABRAL, A. C. A.; SANTOS, S. M. D.; PESSOA, M. N. M. Satisfação no serviço público: um estudo na Superintendência Regional do Trabalho e Emprego no Ceará. REAd. Revista Eletrônica de Administração, v. 20, n. 1, p. 90-113, 2014.

BRUNELLI, M. G. M. Motivação no Serviço Público. MBA em Gestão Pública. Faculdade IBGEN - Instituto Brasileiro de Gestão de Negócios. Porto Alegre, RS, 2008.

CRESWELL, J. W. Projeto de Pesquisa. Métodos Qualitativo, Quantitativo e Misto. Tradução Magda Lopes. - 2 ed. - PORTO ALEGRE: ARTMED, 2007.

EMBASA, Intranet. Avaliação de desempenho por competência. Guia de Orientação para o ano de 2014. Disponível em: < http://www.embasa.intranet/index.php?option=com_ jdownloads $\&$ Itemid=1316\&view=viewdownload\&catid=33\&cid=786 > . Acesso em 01 Nov 2014.

GOMES, A. A. P.; QUELHAS, O. L. G. Motivação dos recursos humanos no Serviço Público. Um estudo de caso sob dois ângulos teóricos. REAd. Revista Eletrônica de Administração, v. 9, n. 5, p. $1-18,2003$.

MASCARENHAS FILHO, C. C, 2009. Motivação: Uma Ferramenta de Gestão nas Organizações. XIII Encontro Latino Americano de Iniciação Científica e IX Encontro Latino Americano de PósGraduação - Universidade do Vale do Paraíba

PIRES, José Calixto de Souza and Macêdo, Kátia Barbosa. Cultura organizacional em organizações públicas no Brasil. Rev. Adm. Pública, Fev 2006, vol.40, no.1, p.81-104.

RODRIGUES, W. A.; REIS NETO, M. T.; GONÇALVES FILHO, C. As influências na motivação para o trabalho em ambientes com metas e recompensas: um estudo no setor público. Revista de Administração Pública, v. 48, n. 1, p. 253-273, 2014.

SANTOS, W. D. R. O poder da Motivação. VIII Mostra da Qualidade do Poder Judiciário. $30^{\circ}$ Artigo. Tribunal Regional do Trabalho da 23 ${ }^{\mathrm{a}}$ Região. Cuiabá - MT. 2009.

SILVA, P. S. C. Desafios e Potencialidades do Desenvolvimento Humano na Gestão das Organizações Públicas: um olhar sobre a comunicação e o autoconhecimento. Fundação Visconde de CairuFVC/BA. III Congresso da Associação Brasileira de Pesquisadores de Comunicação Organizacional e Relações Públicas - ABRAPCORP, 2009. São Paulo - SP.

VERGARA, S. C. Métodos de Pesquisa em Administração. São Paulo: Atlas, 2005.

VIEIRA, et al, 2011. Motivação na Administração Pública: considerações teóricas sobre a aplicabilidade dos pressupostos das teorias motivacionais na esfera pública. Revista ADMpg Gestão Estratégica, v. 4, n. 1, 2011. Disponível em < http://www.admpg.com.br/revista2011/artigos/12.pdf > Acesso em: 30 Jun. 2014.

Como citar este artigo (Formato ABNT):

VICENTE, P.N.A. e CASSUNDÉ, F.R.S.A. A transformação do comportamento mecanicista diante de fatores motivacionais no ambiente de trabalho da empresa Baiana de Águas e Saneamento de Paulo Afonso EMBASA. Id on Line Revista de Psicologia, Novembro de 2014, vol.8, n.24, p. 114-126. ISSN 1981-1189. 